by a Bayesian approach are described. The error arising from mix composition is of particular relevance to the behaviour of concrete containing admixtures and cement replacement materials. Since the use of such materials is now widespread and existing deterministic models in codes of practice are not applicable, it was disappointing that their influences on prediction of creep and shrinkage are not considered by the authors. The chapter includes methods of allowing for both stochastic creep and other statistical scatter in structural elements, as well as indicating future research needs. Useful references are given for the reader requiring further background knowledge.

The reader will find chapter 6 particularly beneficial. Here, conclusions and recommendations are itemized concisely, and guidance is given to the choice of linear or non-linear solutions for structural analysis. Also, the various views of eminent international workers in part III are informative and provide a balance of opinion.

In summary, the contents of this book, together with extensive referencing, represent the state-of-theart compiled by world authorities, with the emphasis on theoretical aspects. Research students, academics and practising engineers specialising in this subject will welcome such a reference book, and therefore it is recommended for acquisition by civil engineering libraries.

J. J. BROOKS

Department of Civil Engineering,

University of Leeds

\title{
Prestressed concrete design
}

\author{
M. K. Hurst
}

Chapman \& Hall, London, 1988. $234 \mathrm{~mm} \times 152 \mathrm{~mm} .278$ pp. Illustrated, hardback. ISBN $0412289601 . £ 22.50$

This text, which is aimed at both students and practising engineers, gives a good summary of the behaviour of prestressed concrete in its 13 chapters.

The first three chapters cover material which is an essential prerequisite to a thorough understanding of the subject. The first covers basic behaviour and includes a good description of the forces acting on the various parts of the structure. These include such facts as the coincidence of the line of thrust with the cable profile; an idea too often taken for granted by those with experience but often such a hurdle for the student to appreciate. Chapters 2 and 3 cover material properties and the principles of limit state design, the latter being treated correctly but with little attempt at a discussion which could assist students through the debate which is currently in progress.

Chapter 4, which deals with losses, and chapter 5 on the analysis seem strangely out of sequence; the chapter on losses assumes an ability to analyze the structure, before the chapter that explains it. However, given that the book is unlikely to be read 'cover to cover', this should not cause too many problems. The analysis chapter itself discusses most of the cases likely to occur, including cracked and uncracked elastic behaviour, 'accurate' and 'BS 8110' ultimate load behaviour, and the effect of unbonded or untensioned reinforcement.

Deflections are covered in chapter 6 , but with only a brief discussion of the long-term effects, which is barely adequate for a subject which is so important for prestressed concrete structures. The chapter on shear also seems to be a bit thin, relying on application of the shear provisions of BS 8110 only, with little discussion of the relevance and correctness of the formulae being used.

The chapter on design of sections is rightly separated from that on analysis, a distinction not usually made with sufficient force in student texts, and the Magnel diagram is correctly given prominence in the design procedure, although this is not followed up in the later chapter on design examples. There are also interesting, but brief, discussions on the choice of the section itself.

A long, and on the whole good, chapter on composite construction is followed by a less good chapter on the behaviour of indeterminate structures. Methods are presented for the determination of the line of thrust of a cable, and a slightly misleading example of how to determine a concordant profile is given, without mentioning the more complex and realistic problem of how to determine such a profile that actually satisfies constraints on the line of thrust at all points along the beam. Redistribution at the ultimate load is covered briefly, and the awkward question of whether to include parasitic moments at the ultimate load is discussed in a very unsatisfactory manner.

The final chapters discuss prestressed flat slabs (quite well), and give some brief design examples. These are more illuminating as examples of good handwriting and layout of calculation, rather than as 
design guidance. They include many examples of making an assumption, without explanation, which subsequent calculation shows to have been justified. A much more worthwhile example would be to discuss what to do if the original assumption is not found to be valid.

The main criticism that the reviewer has about the book is its slavish following of BS 8110 , as though this code contained equations which covered the actual behaviour of prestressed concrete, as opposed to 'deemed to satisfy' clauses which are usually based on conservative approximations. The code formulae are built around assumptions, which are not stated in the code, the validity of which is unknown to designers of any particular structure. A longer and more general treatment would have allowed these points to be put into context.

Despite these points, the book is probably the best text around that relates to prestressed concrete behaviour in a British (i.e. BS 8110) context and, as a wellwritten introductory text at a reasonable price, it is worthy of a place on the bookshelves of many undergraduate and postgraduate students. For more experienced engineers, it should perhaps be used more as a general introduction, to be read in conjunction with more detailed texts.

C. J. BURGOYNE

Department of Engineering and Fellow of Emmanuel College, University of Cambridge

\title{
Brick and block masonry
}

\author{
Editor: J. W. de Courcy
}

Elsevier Applied Science, Barking, 1988. $234 \mathrm{~mm} \times 152 \mathrm{~mm} .3$ volumes: 594 pp., 658 pp., 666 pp. Illustrated, hardback. ISBN 1851662626 ; ISBN I 851662634 ; ISBN $1851662642 . £ 160$ (3 volumes)

This book is the proceedings of the eighth international brick and block masonry conference, held in Trinity College, Dublin on 19-21 September 1988

Previous conferences, held every three years, in the series have taken place in Austin, Stoke-on-Trent, Bruges, Essen, Rome, Washington and Melbourne. Between these conferences are the international symposia on load-bearing brickwork which are held in London and are organized by the British Masonry Society (formerly by the British Ceramic Society).

The Dublin conference was the first to expand its scope to include blockwork, and this change is also reflected in the symposia, which now concentrate on masonry as opposed to ceramic units. These changes are important as they reflect the somewhat greater co-operation between brick and blockmakers than in the past, and indicate an awareness that it is the masonry industry that competes in the walling market and not small parts of it. This greater unity of purpose is also important in the field of codes and standards, where the action is on an international front. This was emphasized by the fact that, in conjunction with the conference, the Technical Committee of TC 179 of the International Standards Organization took the opportunity to meet to further work on drafts of standards for the design of unreinforced masonry structures and for methods of test for masonry.

The proceedings are published in three volumes and contain 174 papers on the structural use of brick, concrete block and stone masonry. The papers con- sider both old and innovative materials, mortars, reinforcement and prestressing, wall ties, veneers and cladding and composite forms. Chapters deal with various loading conditions: general, concentrated, eccentric, lateral, shear, torsional, thermal and seismic. The book reports on the examination and testing of existing buildings, and also on their reconstruction and strengthening. The editor detects in the papers an increase in interest in the masonry arch as against previous conferences and questions whether this is related to an increase in interest in the use of compression to retain stability. It is also relevant to note that there are a good number of papers dealing with restoration and rehabilitation, which reflects a large current market. Also there are a significant number of papers related to techniques of test for and performance studies of buildings in use; this is consistent with a recommendation from the Institution of Civil Engineers' report on research needs.

This collection of papers from 25 countries represents the present state-of-the-art in masonry design and construction, and emphasizes areas in which research is active. This book will be of interest to those involved in civil engineering, structural engineering, concrete technology, building science and architecture.

G. J. EDGELL

Head of Building Materials Division, British Ceramic Research Ltd, Stoke-on-Trent 